\title{
Discourse markers and lecture structure: their role in listening comprehension and EMI lecturer training
}

\author{
María Ángeles Martín del Pozo \\ maryange@dlyl.uva.es \\ Universidad de Valladolid, Spain
}

\begin{abstract}
Listening comprehension of lectures in L2 contexts is a widely researched topic. Findings have been applied to both materials and course design. This paper focuses on findings about the facilitative role in comprehension of those discourse markers (DM) which signal lecture structure. These markers can also be of assistance in L2 contexts such as new English Medium Instruction (EMI) scenarios, where the lecturer is not a native speaker of English. A small-scale investigation about the presence of these markers in EMI lecturer discourse is presented. Findings indicate that lecturers need a more overt signalling of lecture phases and a wider stylistic variety enabling them to do so. The paper concludes by suggesting that EAP materials for training students in listening comprehension could be a good resource to provide the lecturer with a repertoire of linguistic tools to structure their lecturers and in consequence facilitate comprehension for students.
\end{abstract}

Keywords: listening comprehension, academic language, bilingual education, teacher education, discourse markers

\section{INTRODUCTION}

Flowerdew (1994) defended the undeniable importance of teaching listening comprehension skills in a language other than the mother tongue. The reason for this was the high number of students learning through a foreign language at that time. Today, more than two decades later, his vindication becomes even more vital with the proliferation of English Medium Instruction (EMI) and other bilingual education approaches. Practice has outpaced the provision of qualified and prepared teachers. Surveys reveal that Spanish teachers at all educational levels are more concerned with linguistic than with methodological training. Though the partiality of this vision is arguable, the urgency of language upskilling is evident for in-service and prospective EMI teachers. This paper aims to advocate and propose the utility of academic listening comprehension materials as a valid resource to support EMI teachers in the process of class preparation. Research about the role of discourse markers in lecture 
comprehension and the learning materials derived from these findings could now be transferred to these new scenarios of L2 listening comprehension. The paper will open with a reflection on the lecture as an academic oral genre and the role of discourse markers to signal phases and facilitate comprehension. Next, the actual presence of these DM in EMI lecturer discourses will be observed to identify linguistic needs. Finally, some academic listening materials will be suggested as resources to cover those needs.

\section{LISTENING COMPREHENSION IN LECTURES}

\section{II.1 Academic listening: understanding lectures}

Some teaching methods such as tutorials, seminars and practical sessions are gaining momentum in the European Higher Education Area (EHEA). However, the lecture continues to be "a cornerstone of many tertiary level courses and, due to the increase in student numbers, it is likely to remain so" (Exley and Dennick 2009: 10). Therefore, it is currently relevant to contribute to a better understanding of how lectures are comprehended and of how to deliver them successfully, both for L1 and L2 contexts.

In lectures, the use of language is complex. There are significant differences between listening to academic discourse and more general listening events. Miller (2002) points out some of them:

- academic discourse presents a special disciplinary orientation,

- it is delivered to an audience in particular ways,

- the underlying rhetorical structures are different from other conversational contexts.

Complexity in lectures does not only affect the language. The situation itself is also multi-faceted. The listener has to integrate information coming from different channels (auditory, visual and perhaps kinetic). This is one of the main differences between the lecture comprehension process and the comprehension process of other oral genres. Thus, knowledge of the factors affecting L2 academic listening comprehension could provide benefits (Hyland 2009: 97). These factors have been the center of attention in numerous research studies, among which Academic listening (Flowerdew 1994) is still 
said to be the most comprehensive work. The main argument underlying the whole book is that knowledge of how lectures are comprehended in L2 can be applied to:

1) Teaching students to understand lectures in a second language, and

2) Assisting lecturers to facilitate comprehension.

Or in other words, as Mendelssohn (1998) reflects:

The call for greater support in academic listening for non-native speakers comprises two aspects: the need to help students to help themselves, and the need to educate lecturers when they have classes with significant numbers of international students (p.92).

If we transfer this to EMI contexts where the lecturer is a non-native speaker of English, the application of this information to support and educate lecturers translates differently than it would in the case of native speakers. Subsequently, the question is what knowledge about lecture comprehension derived from these studies is useful for the linguistic education of teachers in EMI contexts.

A consideration of the factors affecting lecture comprehension could provide answers. Any good quality teaching practice should ponder these factors, but perhaps they present distinctive connotations in L2 contexts. Some of these aspects are tightly related to personal style (such as speed of delivery). Others, though depending on style, are "trainable". Some of these factors are formal while others are cultural.

The research on L2 academic listening performance emerged from the growing practice of specific language courses for students of content in L2 (Chaudron and Richards 1986). The findings of this research are potential input for instructional materials, curriculum design and teacher training. This paper focuses on some of the findings about the formal factors which affect lecture comprehension and on their derived pedagogical implications. That is to say, the overview of some of the aspects revealed by the research provided in this paper endeavors to consider those which could be transferred to assist lecturers in delivering more comprehensible classes.

\section{II.2 Formal elements in the lecture: phases and discourse markers}

The use of certain rhetorical markers is a major feature of the language of lectures. These markers are lexical phrases which help to signal the most important content, and to indicate moves in argumentation or the boundaries of non-essential information. 
These discourse markers (DM henceforth) are one of the most studied formal elements in L2 and L1 lectures.

The state of the art (Bellés-Fortuño 2008) shows heterogeneity in the concept and taxonomies of DM. Discussion about them is beyond the scope of this paper, since it tries to maintain an applied and didactic orientation. Chaudron and Richards (1986) provided one of the first and most widely used categorizations, which distinguishes between micromarkers and macromarkers. Though this classification has also been discussed, their study opens up a series of investigations about the role of markers in understanding lectures.

This paper will focus only on macromarkers, that is, metadiscursive comments on how the lecture itself will be organized, or phrases which signal to the listener what is coming next (e.g., Today, we'll talk about; Now, let's take a look at; We'll come back to that later).

The label DM will be maintained to refer to them. This option is justified by the phase model (Young 1994), which identifies a macrostructure of the lecture independent from the discipline or other situational factors. It is a model allowing the lecture to be approached as a genre. Phases are:

Strands of discourse that recur discontinuously throughout a particular language event, and, taken together, structure the event. These strands recur and are interspersed with others resulting in an interweaving of threads as the discourse progresses. (1994: 165)

This model fulfills two requirements that are relevant for this research paper. Firstly, the model has a didactic purpose, since the aim of a detailed description of lectures is to make them more comprehensible for students. Secondly, this phase model goes beyond traditional linear models such as "introduction, middle, end", which cannot seize the complexity of the lecture as a discursive act. Young's model is not linear but recurrent. In addition, Young identifies some linguistic elements that are distinctive in each of the phases. DM are a group of these elements which, for example, signal or delimit a phase. The same author endorses the relevance of recognizing these linguistic features for both lecturers and L2 students: "an acquaintance with the correct schematic patterning of lectures will greatly assist students" (p.173). Table 1 recaps this phase model. 
Table1. Lecture phases (Young 1994)

\begin{tabular}{|c|c|c|}
\hline \multirow{3}{*}{ 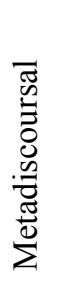 } & $\begin{array}{l}\text { Structuring } \\
\text { Discourse }\end{array}$ & Lecturer indicates the direction that they will take in the lecture. \\
\hline & Conclusion & Lecturers summarize points made during the class. \\
\hline & Evaluation & $\begin{array}{l}\text { The lecturer reinforces each of the other strands by evaluating } \\
\text { information which is about to be or has already been transmitted. }\end{array}$ \\
\hline \multirow{3}{*}{ 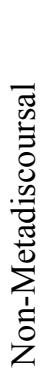 } & Interaction & $\begin{array}{l}\text { The lecturer establishes contact with students to check if they have } \\
\text { understood or to reduce distance. }\end{array}$ \\
\hline & Content & The lecturer transmits theoretical information. \\
\hline & Exemplification & The lecturer explains theoretical concepts through concrete examples. \\
\hline
\end{tabular}

As already said, DM are an important element in this model. DM in lectures have been approached from two perspectives (Bellés-Fortuño 2008: 112):

1. The role and function of these DM in L1 lectures (from the perspective of the lecturer-sender and the genre per se),

2. The role of those DM in lecture comprehension in L2 (from the perspective of the student-receiver).

This second group has been more widely researched that the first one. Before summarizing the main contributions of studies in this line (section II.4), it is convenient to dedicate a section to reflect on the importance of DM in listening comprehension.

\section{II.3 DM and listening comprehension}

Listening is a complex skill which involves physiological and cognitive processes in conjunction with the processing of contextual information. A brief overview of the cognitive elements involved in listening will raise awareness of the implications for listening in L2 contexts. This section relates DM to both the sources of knowledge which aid listening comprehension and the processes of listening comprehension.

Firstly, Anderson and Lynch's model of listening comprehension (1988: 13) identifies three main sources of knowledge:

- schematic knowledge (background knowledge and schemata), 
- contextual knowledge (situation and context), and

- systemic knowledge (knowledge of the language system at the phonological, lexicosemantic, morphosyntactic, and discursive levels).

$\mathrm{DM}$ are elements of the language system, and therefore knowledge of them can potentially enhance comprehension. In addition, DM signal the different phases in a lecture (Young 1994). This is related to schematic knowledge. Students are supposed to have lecture schemata in their L1 and this knowledge could be used to understand lectures in L2.

Other theoretical models provide information about the processes involved in listening. Two main types can be identified: top-down processes and bottom-up processes. In the first type, the listener builds a conceptual framework for comprehension using context and prior knowledge stored in long-term memory (topic, genre, culture, schema knowledge). On the other hand, bottom-up processes imply the construction of meaning by building up from smallest units of meaning (phoneme-level) to increasingly larger ones up to discourse-level elements. These processes do not exclude each other but interact depending on the purpose of the listening and on the listener's skills (Vandergrift 2004). Understanding the unit of meaning constituted by DM favors bottom-up comprehension processes.

Finally, the microskills models should be considered. Richards' (1983) highly cited paper provided a detailed list of skills needed for conversation and academic lecture speech, which others have followed (Mendelssohn 1998). Richards' taxonomy (1983) includes "the ability to recognize the role of DM for signaling the structure of the lecture". In this case, top-down processes are promoted. Hence, knowledge of DM is likely to foster both comprehension processes. Perhaps this is one of the reasons for their presence among the skills needed for comprehension ability.

\section{II.4 DM in lecture comprehension}

The significance of DM in lecture comprehension is sustained through their permanence as a focus of interest for many researchers. Chaudron and Richards' pioneering investigation (1986) concluded that macromarkers signaling major transitions and emphasis in a spoken academic lecture helped successful recall. Since then, other researchers have approached the question by combining different variables such as the 
type of markers or the kind of evaluation process. Most of the studies agree on the facilitating effect of DM, especially macromarkers and metadiscourse in contexts where the student is not a native speaker of the language of instruction.

The methodology followed in these studies was similar. Firstly, an experimental group received the lecture with DM, while a control group received the same lecture without those DM (Chaudron and Richards 1986, Eslami and Eslami-Rasekh 2007, Flowerdew and Tauroza 1995, Jung 2003, Morell 2004, Reza et al. 2012, inter ali.). Secondly, students' comprehension is checked by means of questions, tests or the notes taken. In the same way, Tehrani and Dastjerdi (2012) showed that cohesion and coherence in the written compositions of students who received the lecture with DM was higher than in those by students who received the lecture without DM.

Some other studies included an interventional step: some students received explicit instruction on DM. Results show that these did better than students who had not been explicitly taught DM (Smit 2006). Smit's intervention program focused on training the students to notice when and how lecturers use DM to verbally signpost the different movements in the lecture. Thus, DM achieve a twofold utility as indicators of the structure of the discourse and as potential aids in training listeners to understand better.

The consensus about the presence of DM as a facilitator of comprehension seems to be general. The disagreements among these studies may be rooted in the type of markers studied, the students' language proficiency or the test employed. This paper will not discuss such disagreements.

In conclusion, the facilitative role of DM to signal lecture phases (Young 1994) is implicit in the findings of most of these studies. As a result, pedagogical implications derived from them include the teaching of these elements to students and the recommendation for lecturers to incorporate them in their discourses. Accordingly, Mendelssohn (1998) offers eight suggestions for lecturers, all derived from the studies and experiences compiled in Flowerdew (1994). The third of Mendelssohn's suggestions reads: "train lecturers to insert many more overt DM that highlight the overall structure of the lecture" (p. 93). Eslami and Eslami-Rasekh (2007) emphasize the "teachability" of these elements: 
The use of discourse markers can be considered as an area of strategic competence that can be taught and may have an immediate effect on comprehension. This means that nonnative speakers can compensate for skills that they lack by using appropriate strategies. (p.35) (emphasis added)

Materials design and methodology for the teaching of these elements are based on the findings of studies on academic listening comprehension like the ones reviewed in this section. Benefits have extended to lecturers and to students. However, with the growing expansion of CLIL/EMI, content lecturers are not necessarily native speakers. The next section deals with some of the implications of this reality.

\section{LECTURES IN L2: THE NEW SCENARIOS OF ENGLISH MEDIUM INSTRUCTION}

\section{III.1 New contexts of English medium instruction: forces behind and challenges ahead}

The EHEA, the internationalization of universities, and some European linguistic policies are promoting the teaching of non-linguistic disciplines in a foreign language at all educational levels. This is known as CLIL (Content and Language Integrated Learning) in English and AICLE (Aprendizaje Integrado de Contenidos y Lengua Extranjera) in Spanish. In higher education, the label English Medium Instruction (EMI) is preferred. EMI does not necessarily imply the dual focus on language and content. In fact, a distinguishing feature of EMI is the non-existence of linguistic objectives (Smit and Dafouz 2012). EMI is content-driven and lecturers are not language teachers but content experts. However, some improvement in students' language skills is always expected in bilingual programs.

The speed of development and the expansion of these practices have no precedents and the forces behind them (such as those mentioned at the beginning of the section) can be easily identified (Coleman 2006). This celerity of implementation implies that praxis is outpacing theory. Therefore CLIL/EMI conceptual and theoretical frameworks are still under construction and a "theory-lessness" (Dalton-Puffer 2007: 10) permeates this trend.

Another important challenge at all educational levels is teacher training (Martín del Pozo 2013). The profile of EMI lecturers is moving from native speakers to speakers of 
English as a lingua franca (ELF). Before the current CLIL/EMI boom, content lecturers were very frequently native speakers or had far more proficiency than students. However, this is no longer the case, or at least not in Spanish Universities (Lasagabaster and Sierra 2010). Language level is one of the main difficulties and reasons for lecturers to be reluctant to teach their content subjects through English. Some studies (see compendium for Spain in Martín del Pozo 2015) show that teachers do not consider themselves in need of methodological training. Their main perceived need is only linguistic upskilling.

There is also a debate about the linguistic needs and the language qualification required for content lecturers to take EMI courses (Halbach and Lázaro 2015). Teacher training is left to each individual institution and the materials available are scarce. A serious approach to this substantial challenge could start by describing how lecturers are actually teaching through English. The next section presents some classroom research about lecturer discourses.

\section{III.2 DM in Spanish EMI teacher discourses}

The preceding sections have centered on the significance of DM in lectures and their facilitative role in the process of lecture comprehension in L2. Two main pedagogical implications are derived:

1. The convenience of training students to identify and comprehend these elements.

2. Educating lecturers for a conscious use of DM could be beneficial.

Regarding this second pedagogical implication, a first step to be taken is to observe the frequency and type of DM employed in teacher discourses. Several studies have been conducted on EMI lecturer discourses in the Spanish context. The research group CLUE (Content Learning in University Education) gathered a corpus of oral data from different universities in the Comunidad Autónoma de Madrid. One of the novelties of this research group is to approach the discourse of a non-native speaker of English. Previous investigations have centered on strategies employed by native speakers of English teaching to international audiences or on these international audiences' understanding of lectures by native speakers. 
Núñez and Dafouz (2007) studied four content lecturers' teaching through English and identified the different phases of the lecture (Young 1994). However, phase and phase change were only explicitly indicated in a small number of occasions. In addition, the use of some explicit markers such as "for example" did not correspond to a signaling value. These researchers forewarn that both cases (scarce signaling or ambiguous signaling) may be a hindrance for comprehension.

A following study (Dafouz and Nuñez 2010) expanded on and enhanced the research conducted in 2007. This time, the analysis did not only identify lecture phases but also the functional elements in each of them, with especial attention to DM. The resources with a signaling function of three Spanish lecturers teaching through Spanish were contrasted with those used when lecturing through English. Findings reveal that lecturers transfer linguistic tools from L1 to L2. However, L2 productions show a lower frequency, precision and stylistic variety. Explicit signaling of phase change is considerably inferior to the frequency and variety of resources when changing phase in Spanish. Conclusions indicate that resorting to these types of resources may strongly depend on personal teaching style and on the fact that lecturers tend to reproduce in L2 their own style in L1. However, very specific linguistic needs are derived from these results. One of them is the convenience of providing linguistic tools to signal phases, together with the awareness of their utility for the students to comprehend lectures. These studies call for further research in parallel contexts, such as the one addressed in the next section.

\section{CONTEXT, RESEARCH QUESTIONS AND METHODOLOGY}

This section describes a small-scale investigation conducted in a Spanish EMI context. The long-term aim is to assist lecturers with the language needed to teach in English, in particularly with DM to signal lecture structure. The first step before devising a pedagogical intervention, and therefore the immediate aim, is to observe the current presence of DM in these teachers' discourses.

\section{IV.1 Research question}

The following specific research questions attempt to fulfill the aim of describing the presence of DM in lecturer discourses and identifying linguistic training needs. 
1. How many occurrences of the DM are there in the lecturer discourses?

2. What is the linguistic form of these DM?

\section{IV.2 Context}

The Escuela de Ingeniería Informática de Segovia (EIISG) (Universidad de Valladolid, Spain) was the first public higher education institution to offer a bilingual degree in Computing in the Comunidad de Castilla y León. EMI was an optional practice from 2006 to 2011 within the program Ingeniero técnico de informática de gestion. The subjects taught through English ranged from Microeconomics, Operating systems, Software engineering, Math, Physics, Information Systems, Programming, and other related areas of knowledge. The number of credits in English increased from 26 to 117 over this five-year period. The attitudes and perceptions of students and lecturers for the first two years of the experience were reported in Martín del Pozo (2008a and b) along with some narratives of lecturers' difficulties, strategies and achievements.

At the EIISG, 'The shift towards L2 medium education in English does not correlate with the introduction of CLIL' (Marsh and Laitinanen 2005: 2). This means there are no explicit language objectives at the institutional or the individual level at the university. This is a widespread trend in Spanish universities. Nonetheless, students' linguistic competence is always expected to benefit from any bilingual program.

Six lecturers were videotaped during the delivery of a sample lecture. The transcriptions of the verbal language formed a corpus whose most relevant features are specified in Table 2:

Table 2. Corpus description

\begin{tabular}{|l|l|l|l|l|} 
Lecturer & Topic & $\begin{array}{l}\text { Recording time } \\
\text { (minutes) }\end{array}$ & $\begin{array}{l}\text { Number of } \\
\text { words }\end{array}$ & $\begin{array}{l}\text { EMI experience } \\
\text { (years) }\end{array}$ \\
\hline Lecturer 1 & Processes in operating systems & 31 & 2,580 & 2 \\
\hline Lecturer 2 & $\begin{array}{l}\text { Information representation in } \\
\text { Quantum arithmetic }\end{array}$ & 27 & 2,140 & 5 \\
\hline Lecturer 3 & Consumer preferences & 40 & 3,300 & 3 \\
\hline Lecturer 4 & Graph theory & 51 & 2,650 & 5 \\
\hline Lecturer 5 & Basic concepts of mathematics & 22 & 2,273 & 4 \\
\hline Lecturer 6 & Gauss's Theorem and applications & 36 & 3,470 & 4 \\
\hline Total & Number of lectures: 6 & 207 minutes & 16,413 words & \\
\hline
\end{tabular}


The six lecturers were selected on the basis of gender, subject and their having more than two years' experience teaching through English. Their discourses were analyzed to observe DM. This paper reports only on those DM used to signal the opening (openers), the sequencing (sequencers) and the introduction of new topics (verbal topicalization) in the discourse structuring phase.

\section{IV.3 Methodology}

The linguistic analysis of these data required the design of a taxonomy based on previous models. Among the available models used in previous studies, such as Chaudron and Richards (1986) or Bellés-Fortuño (2008), the most suitable for our purpose were the lecture phases model (Young 1994), already described in II.2, and the taxonomy which Dafouz and Nuñez (2010) used in their analysis. Since this paper centers only on DM for opening, sequencing and introducing new topics, an abridged version of the taxonomy is presented.

Table 3. Abridged taxonomy (Dafouz and Nuñez 2010: 220)

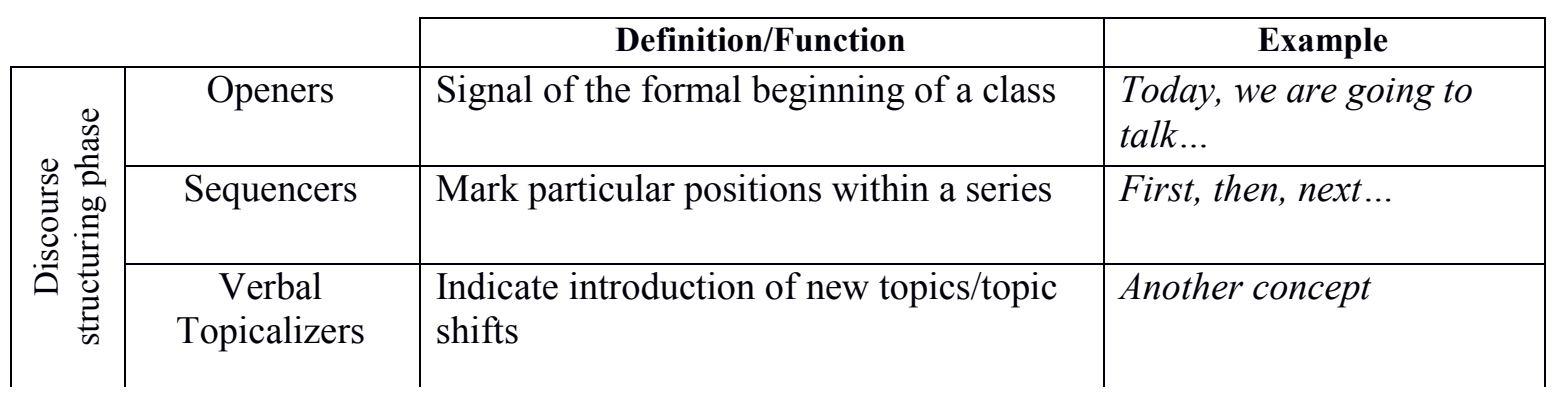

The opening move in the research process was to identify what constitutes a DM in the six lecturers' discourses. Once these markers had been identified, the analysis of each of them was undertaken following the taxonomy described above. Both qualitative (formal features) and quantitative (number of occurrences) information was used. The main relevant findings are now summarized.

\section{RESULTS AND PEDAGOGICAL IMPLICATIONS}

\section{V.1. Results}

This is a small-scale investigation in a bilingual degree at a Spanish university. Results are not unexpected to be similar to those of previous studies in EMI parallel contexts, 
such as the research on lecturers' discourse by Dafouz and Nuñez (2010). These results provide important insights into the features of Spanish lecturers using English to teach content subjects.

Nevertheless, as Figure 1 shows, markers to structure lectures prevail over the other types, although their presence is limited and characterized by a lack of stylistic variety (see Tables 4 and 5).

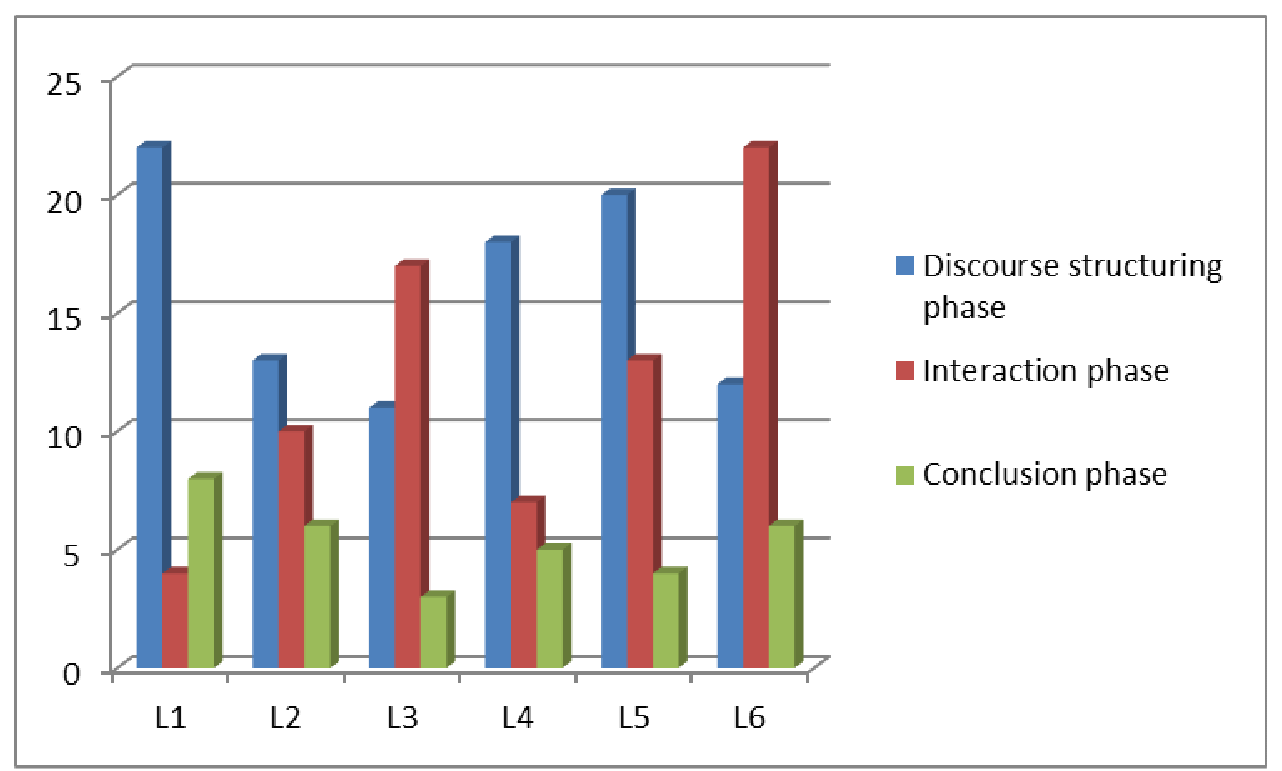

Figure 1. Distribution of DM per lecturer in lecture phases

As regards the qualitative features of the DM, the following Tables 2 and 3 provide an overview of markers produced to open the lecture, to indicate sequence, and to introduce new topics. 
Table 4. DM in lecturers 1, 2 and 3

\begin{tabular}{|c|c|c|c|c|}
\hline & Lecturer 1 & Lecturer 2 & Lecturer 3 \\
\hline \multirow{3}{*}{ 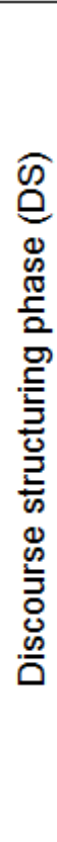 } & 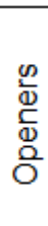 & $\begin{array}{l}\text { Today's lecture is about } \\
\text { The lecture today is } \\
\text { We will talk/ } \\
\text { We will describe } \\
\text { The objectives of this talk will } \\
\text { be }\end{array}$ & $\begin{array}{l}\text { In this talk i am going } \\
\text { We will introduce, we will } \\
\text { see if } \\
\text { In this very, very introductory } \\
\text { lecture we just work with }\end{array}$ & $\begin{array}{l}\text { This is the first less } \\
\text { lesson in the course } \\
\text { In this lesson we will } \\
\text { talk about } \\
\text { The target of this } \\
\text { lesson is }\end{array}$ \\
\hline & 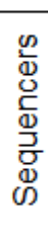 & $\begin{array}{l}\text { And, also } \\
\text { The last, } \\
\text { The third, } \\
\text { Finally }\end{array}$ & $\begin{array}{l}\text { First of all } \\
\text { The first thing }\end{array}$ & $\begin{array}{l}\text { First } \\
\text { The second } \\
\text { Once } \\
\text { Until now }\end{array}$ \\
\hline & 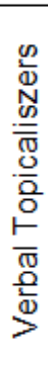 & $\begin{array}{l}\text { The main notion of this } \\
\text { class, } \\
\text { Another possibility in time } \\
\text { share systems (2) } \\
\text { Another objective of this } \\
\text { lecture was } \\
\text { What is a process? } \\
\text { The basic issues of these } \\
\text { notions are related in this } \\
\text { slide } \\
\text { We have the. }\end{array}$ & $\begin{array}{l}\text { (First of all) we should } \\
\text { tackle with } \\
\text { Let's follow } \\
\text { So the point here in this } \\
\text { question } \\
\text { The problem here is the } \\
\text { following } \\
\text { This has a problem, } \\
\text { The rule is the following }\end{array}$ & $\begin{array}{l}\text { For example } \\
\text { What is a market } \\
\text { basket? } \\
\text { A new property of... }\end{array}$ \\
\hline
\end{tabular}

Table 5. DM in lecturers 4, 5 and 6

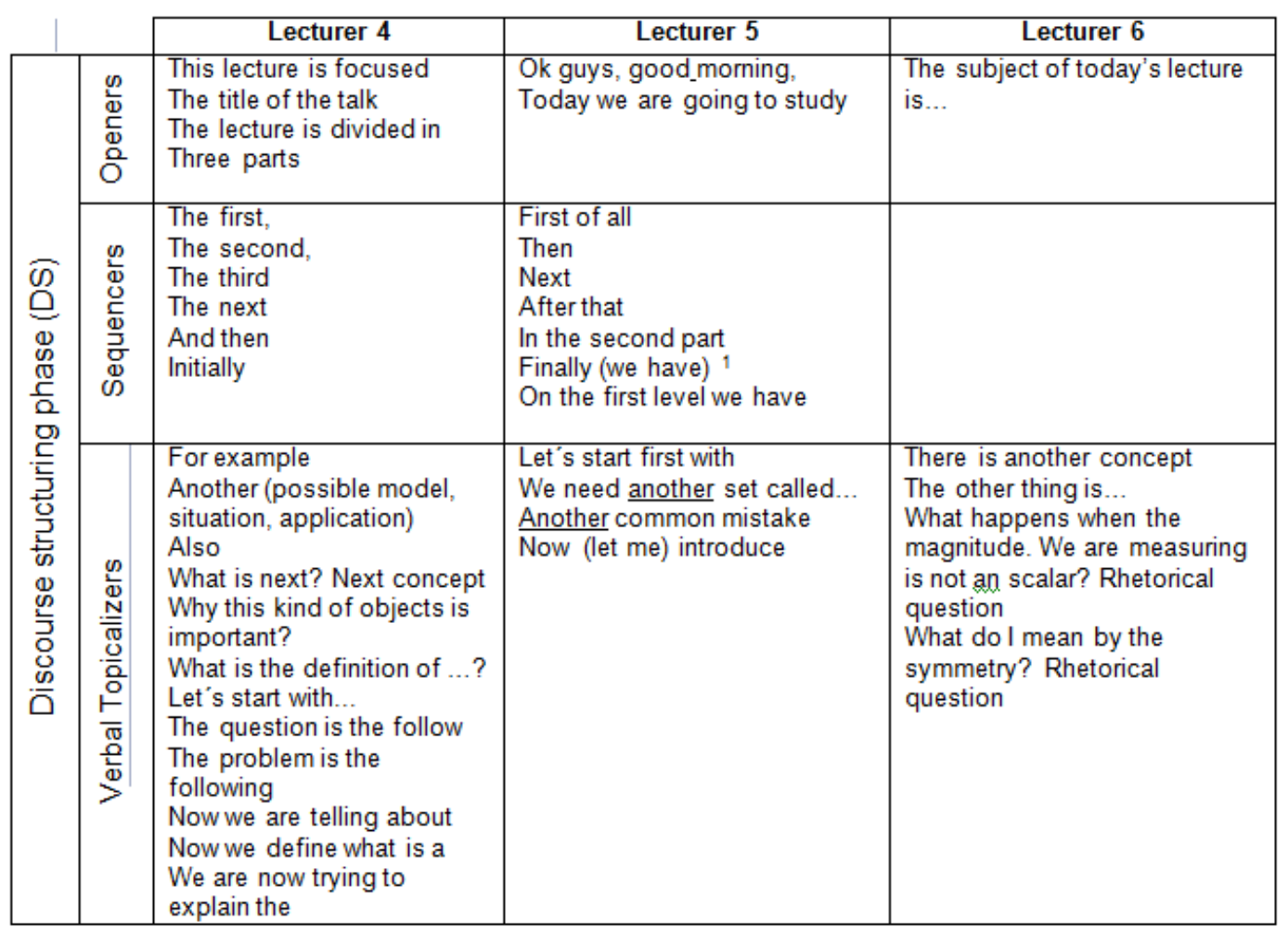


The frequencies and categories in the lecturers' discourses provide useful information about individual linguistic needs. However, commenting on and discussing them in detail is far beyond the extension and scope of the present paper. What is relevant is that, though they do have a battery of resources given their expertise in lecturing in L1, these are seen to be repetitive and stylistically weak.

\section{V.2. Pedagogical implications}

Indications or teacher training implications formulated in studies about the importance of DM in listening comprehension fall under the general label "train lecturers". They need to be specified in language contents. This paper contributes to the specification, as the pedagogical implications derived from the findings are evident and match those proposed by similar studies. The first one is that EMI lecturers require linguistic tools to signal lecture phases. Materials in section VI could provide this instruction.

A second implication is the convenience of raising lecturers' awareness about the significance of introducing such DM. The materials recommended in section VI can potentially make them aware.

A third implication concerns the reality that assisting non-native speakers to deliver lectures will concurrently have an effect on students' comprehension. This is of great importance, as there is a tendency towards emphasizing the instrumental character of listening comprehension: "learning to listen in the L2 and learning the L2 through listening" (Rost 2002: 91). Although the explicit teaching of language is not among the duties of content teachers (neither are they trained to teach language), teachers are linguistic models of the academic and discipline discourses. DM are part of academic discourse and students are more likely to learn them if heard in lectures.

Finally, language training would perhaps be more welcomed and accepted if it could be overcome autonomously. The problem is the dearth of CLIL/EMI teacher-training materials for autonomous work. However, there are materials available, though they were not initially designed for that purpose. This paper advocates the use of materials targeted towards students who have to attend lectures in English. The new EMI scenarios where lecturers are also non-native speakers (or precisely because they are not native speakers) may also benefit from what has already proven efficient in EAP contexts. 


\section{LISTENING COMPREHENSION MATERIALS: A RESOURCE TO ASSIST EMI LECTURES}

The wide range of materials for learning academic listening demonstrates that the application of knowledge and results derived from research on L2 listening comprehension has targeted students much more than lecturers. For instance, the special research attention paid to how the structure of the lecture is signaled has resulted in instructional materials to train L2 students to identify signposting elements and overall lecture structure. This will only be possible if the lecture is structured and signaled. Lynch (1994) quotes a review by O'Brien (1984) on some materials to teach academic listening comprehension:

As authentic as they sound, however, one has to recognize that special care has been given to the structure of the talks. They have a structure and it is clearly marked. Sadly this is not always the case with the real lecture. Perhaps we should start training the lecturers (O'Brien, 1984, original emphasis).

This could be understood as a complaint about the lack of authenticity in L2 listening comprehension teaching materials and at the same time a call for lecturers to follow the generic conventions of the lecture. In the same line, Jung (2003) warns that EAP listening materials have limitations when compared to authentic lectures. For example, extracts are too short in comparison to real life or intonation is not fully exploited for communication purposes.

In spite of this, EAP listening comprehension materials could be used to learn lecture conventions, both for the native and the non-native speaker. They are often rich in samples of language to signal hierarchical organization in lectures, or language to refer to visual aids and other similar linguistic resources which would be useful for EMI lecturers. Using these already-existing materials is a contribution to "maximize content teachers' access to the generic tools for more explicit signaling of metadiscursive devices" (Dafouz and Núñez 2009: 109).

The resources (books, DVDs and websites) in the following list were originally targeted towards non-native speakers who had to attend content lectures in English. Non-native content lecturers who have to deliver instruction in English could benefit from the linguistic tools available in these resources. The resources are ordered by publication 
date, though there are also expanded new editions. This list illustrates the permanent interest in teaching listening comprehension in academic environments. EMI lecturers may benefit from this heritage by making use of these resources as self-training tools. The list is by no means exhaustive. It aims to serve as an example and indication of where to look for linguistic assistance to teach through English at university.

Table 6 offers examples of the language that EMI lecturers could learn from these materials. The stylistic variety of a single functional resource is evident.

Table 6. Sample of openers

What I intend to say is

What I'd like to do is to discuss

What I intend to do is to explain

In my talk today,

My topic today is

Today, I'm going to talk about

I'm going to talk to you about

Today I want to consider

In this talk, I would like to concentrate on

The subject of this talk is

The purpose of this talk is to

My colleagues and I are going to give a short

presentation on

This talk is designed to

It has to be noted that the table is preceded by some directions to the student who is using this resource to learn listening comprehension skills:

At the beginning of a lecture, or a section of a lecture, the lecturer will give you some idea about the structure of the lecture. Listen for these signals as it will help you understand what the lecturer is saying. (Text preceding Table 6 in one of the recommended materials)

However, the possibility and the utility of a shift from "student learning to listen" to "lecturer learning to speak" is manifest. Similar models to Table 6 are abundant in the following resources.

1) Books

These course books include information about how a typical lecture is organized and strategies for recognizing introductions, conclusions, and digressions. The accompanying DVDs or websites use actual excerpts and transcripts from authentic lectures covering a wide range of topics and academic disciplines. Some strategies for note-taking are also provided. 
Lebauer, R. S. 1988. Learn to Listen; Listen to Learn: academic listening and notetaking. Englewood Cliffs: Prentice Hall

Goodith, Wh. 1998. Listening. Oxford: Oxford University Press

CELTE. 2002. Essential Academic Skills in English: Listening to Lectures. University of Warwick

Salehzadeh, J. 2006. Academic listening strategies: a guide to understanding lectures. Ann Arbor: University of Michigan Press

Beglar, D., Murray, N. 2009. Contemporary topics: academic listening and note-taking skills. New York: Pearson Education

Smit, J and Campel, T. 2009. English for Academic Study: Listening. Reading: Garnet

Parrish, B. 2009. Four point: Listening and Speaking 2, advanced. Ann Arbor, MI: University of Michigan Press

Wennerstrom, A. 1991. Techniques for Teachers a Guide for Nonnative Speakers of English

This reference is provided at the end because it is not targeted towards students but to academic professionals who speak English as a second language. It originated to train non-native teaching assistants in US Higher Education.

2) Web resources

- http://www.englishforacademicstudy.com

Portal to other sites related to Academic English. Some of them are free access. They include clips of lectures and information about the phraseology used in the different phases.

- http://www.uefap.com/ Using English for Academic Purposes. A Guide for Students in Higher Education

Maintained since 1999 by Andy Gillett. Tips and phrases to recognize lecture structure. The information on academic functions can be very useful for content delivery.

- http://www.prepareforsuccess.org.uk/ 
This interactive web tool includes, among other aspects of academia, resources and tips to deal with the language challenge of lecturers in L2.

\section{SUMMARY AND CONCLUSIONS}

The paper opened by highlighting the prevalence of the lecture as an academic genre and thus the significance of understanding how it can be effectively comprehended (sections II.1 and II.2). Reasons for the facilitative role of DM in lecture comprehension have been argued (section II.3). Findings reveal that the presence of DM in lecturer discourse seems to have a positive impact on lecture understanding. On the contrary, the absence of DM may be a hindrance for oral comprehension in academic contexts (section II.4). The production of more DM is advocated in the conclusions of the studies mentioned in II.4. Therefore, if DM are a recommended feature, the first question to be answered is the type of presence of these signposting elements in lecturer discourse in EMI contexts. Discourse analysis of some Spanish lecturers (section III.2) reveals that: 1) there is a small number of DM and lecture phases are implicitly signaled (Dafouz and Nuñez 2010), and 2) Contrastive analysis shows less stylistic variety and less precision in L2 than in L1 (Dafouz and Nuñez 2010).

The small-scale investigation of lecturer discourse at EIISG (section IV) coincides with the earlier findings, with the exception of lacking the contrastive aspect with discourses in Spanish. If a lack of explicit signaling may hinder comprehension, and if EMI lecturers are not producing the desirable number of DM in L2, it seems highly convenient to make lecturers aware of their importance and to train them in the production of markers which clarify lecture structure. Academic listening materials designed to enhance students' lecture comprehension (section VI) could also be employed to provide lecturers with a wide range of linguistic tools for signaling lecture phases.

Other conclusions of this paper are not of that immediate pragmatic nature. Regarding teacher linguistic needs, the research findings summarized in this paper seem to suggest that the debate would be more productive if attention focused on the type of language required for successful EMI lecture delivery rather than concentrating on what language qualifications EMI lecturers should hold. Moreover, most of the CLIL/EMI research to 
date has tended to focus on the product of CLIL/EMI instruction (language learning gains) rather than on the process of teaching and learning. In a modest attempt to fill this research lacunae, this paper has approached one of the elements of the process: DM in lecturers' discourse. The reason for this has been the significant role of DM for lecture comprehension, widely proven by studies on L2 listening comprehension.

Finally, the paper has advocated a new utility of academic listening comprehension materials whose suitability is supported by theoretical models of the listening comprehension process. These materials, originally designed to train students in ESP and EAP contexts, could serve now as a resource for autonomous language upskilling of CLIL/EMI lecturers. These professionals can be considered "a new EAP learner" (Martín del Pozo 2015b). In addition, one of the "synergies of mutual inspiration" (Dalton-Puffer 2007: 297) between ESP and CLIL/EMI could be making use of already-existing and solidly underpinned materials. A second source of inspiration is the application of the knowledge about listening comprehension in L2 lectures to these new L2 scenarios.

\section{REFERENCES}

Bellés-Fortuño, B. 2008. Discourse Markers within the University Lecture Genre: a contrastive study between Spanish and North American Lectures (Unpublished doctoral thesis). Universitat Jaume I: Castellón.

Chaudron, C. and Richards, J.C. 1986. "The effects of discourse markers on the comprehension of lectures". Applied Linguistics 7, 113-125.

Coleman, J. 2006 "English-Medium Teaching in European Higher Education", Language Teaching 39, 1- 14.

Dafouz, E. and Núñez, B. 2009. "CLIL in higher education: devising a new learning landscape”. In Dafouz, E. and Guerrini, M. (Eds.), CLIL across educational levels. Madrid : Santillana, 101-112.

Dafouz, E. and Núñez, B. 2010. "Metadiscursive devices in university lectures: A constrastive analysis of L1 and L2 performance". In Dalton-Puffer, C., Nikula, T and U. Smit (eds.) Language Use in Content-and-Language-Integrated Learning. Amsterdam: John Benjamins, 213- 233. 
Dafouz Milne, E. 2011. "English as the medium of instruction in Spanish contexts: A look at teacher discourse". In Ruiz de Zarobe, Y., Sierra, J.M. and Gallardo del Puerto, F. (eds) Content and Foreign Language Integrated Learning: Contributions to Multilingualism in European Contexts. Frankfurt: Peter Lang, 89-110.

Dalton-Puffer, C. 2007. Discourse in Content and Language Integrated Learning (CLIL). Amsterdam: John Benjamins Publishing.

Eslami, Z. R and Eslami-Rasekh, A. 2007. "Discourse Markers in Academic Lectures". Asian EFL Journal. 9 (1), 22-38.

Exley, K. and Dennick, R. 2009. Giving a Lecture: from Presenting to Teaching. London: Routledge Falmer. ( $1^{\mathrm{a}}$ ed 2004).

Flowerdew, J. (ed.). 1994. Academic listening: Research perspectives. Cambridge: Cambridge University Press.

Flowerdew, J. and Tauroza, S. 1995. "The effect of discourse markers on second language lecture comprehension". Studies in Second Language Acquisition 17, $435-458$.

Halbach, A. and Lázaro, A. 2015. "La acreditación del nivel de lengua inglesa en las universidades españolas: Actualización 2015." Available online here: http://www.britishcouncil.es/sites/britishcouncil.es/files/british-council-laacreditacion-del-nivel-de-lengua-inglesa.pdf .

Hyland, K. 2009. Academic Discourse: English in a Global Context. London: Continuum.

Jung, E.H. 2003. "The role of discourse signaling cues in second language listening Comprehension". The Modern Language Journal 87(4), 562-577.

Lasagabaster, D. and Sierra, J. 2010. "Immersion and CLIL in English: More differences than similarities". ELT Journal 64(4), 367-375. DOI: 10.1093/elt/ccp082

Lynch, T. 1994. “Training lectures for international audiences”. In J. Flowerdew (Ed.). 269-289.

Martín del Pozo, M.A. 2008a. "Impartir asignaturas en inglés: su potencial para el desarrollo de competencias en alumnos y profesores de una ingeniería técnica". 
Jornadas Internacionales Universidad Politécnica de Madrid sobre innovación y convergencia Europea. Universidad Politécnica de Madrid.

Martín del Pozo, M.A. 2008b. "La enseñanza de contenidos en inglés: estudio de caso de una ingeniería técnica en la Universidad de Valladolid”. Actas del I Congreso Internacional de Interacción comunicativa y enseñanza de lenguas. Valencia: Universtitat de Valencia, 381-388.

Martín del Pozo, M.A. 2013. "Formación lingüística del profesorado universitario para la docencia en inglés". Revista de Docencia Universitaria 11 (3), 197-218.

Martín del Pozo, M.A. 2015a. "Teacher education for content and language integrated learning: insights from a current European debate". Revista electrónica interuniversitaria de formación de Profesorado 18 (3), 153-168.

Martín del Pozo, M.A. 2015b. "The needs of a new EAP learner: CLIL teachers". In Shrestha, P. (Ed.) Current Developments in English for Academic and Specific Purposes: Local innovations and global perspectives. Reading: Garnett Education, 115-138.

Marsh, D. and Laitinen, J. 2005. "Medium of instruction in European higher education: Summary of research outcomes of European Network for Language Learning Amongst Undergraduates (ENLU) Task Group 4”. Jyväskylä: UniCOM, University of Jyväskylä.

Mendelssohn, D. 1998. "Teaching Listening", Annual Review of Applied Linguistics, $18,81-101$.

Miller, L. 2002. "Towards a Model for Lecturing in a Second Language". Journal of English for Academic Purposes 1, 145-162.

Núñez Perucha, B. and Dafouz Milne, E. 2007. "Lecturing through the foreign language in a CLIL university context: linguistic and pragmatic implications". VIEWS Vienna English Working Papers. Current Research in CLIL 216 (3) ,U. Smit and Ch. Dalton-Puffer (Eds.), 36-42.

O'Brian, T. (1984) Hearsay. (Review of Lynch 1983). Times Educational Supplement. June 22.

Richards, J. 1983. "Listening Comprehension: Approach, Design, Procedure”, TESOL Quarterly, 17 (2), 219-240.

Rost, M. 2002. Teaching and Researching Listening. London: Longman. 
Smit, U. and Dafouz, E. 2012. Introduction. In U. Smit, U. and E. Dafouz, E. (Eds.) "Integrating Content and Language in Higher Education: Gaining Insights into English-Medium Instruction at European Universities". AILA Review, Volume 25.iii, $1-12$.

Tehrani, A. and Dastjerdi, H. 2012. "The Pedagogical Impact of Discourse Markers in the Lecture Genre: EFL Learners. Writings in Focus". Journal of Language Teaching and Research, 3 (3), 423-429.

Thompson, S. 2003. "Text structuring metadiscourse, intonation and the signalling of organization in academic lectures". Journal of English for academic purposes, 2, 5-20.

Vandergrift, L. 2004. "Learning to listen or listening to learn". Annual Review of Applied Linguistics 24, 3-25.

Young, L. 1994. "University lectures macro-structures and micro-features". In Flowerdew, J. (Ed.), 159-179.

Received: 21 February 2015

Accepted: 12 February 2016

Cite this article as:

Martín del Pozo, M.A. 2016. "Discourse markers and lecture structure: their role in listening comprehension and EMI lecturer training". Language Value 8 (1), 26-48. Jaume I University ePress: Castelló, $\quad$ Spain. $\quad$ http://www.e-revistes.uji.es/languagevalue. $\quad$ DOI: http://dx.doi.org/10.6035/LanguageV.2016.8.3

ISSN 1989-7103

Articles are copyrighted by their respective authors 